\title{
Digital transformation method for value mapping in public management
}

\author{
Igor Petrov ${ }^{1, *}$, Maxim Zemtsov ${ }^{1}$, and Andrey Butyrin ${ }^{2}$ \\ ${ }^{1}$ Vyatka State University, Moskovskaya str., 36, Kirov, 610000, Russia \\ ${ }^{3}$ Moscow State University of Civil Engineering, 129337, 26, Yaroslavskoe Shosse, Moscow, Russia
}

\begin{abstract}
This study addresses the issue of developing a model of value proposition in public management field. Value mapping is a vital feature for a digital modelling and analysis methods. The developed method is based on the Alexander Osterwalder business model canvas. An approach makes it possible to track the system intra-relations during a problem solving due to a value proposition and, accordingly, changes in the public management model. It represents an essential part of reference model for public management architecture and reveals the dependence of local municipalities on federal and regional state authorities due to financial shortage.
\end{abstract}

\section{Introduction}

The digital transformation that is currently going on in societies all over the globe has an effect on citizens, businesses and public sector organizations. One of the key actors in the digital transformation of societies are public administrations [1]. The scientific and technological revolutions lead to the fact that the role of science in the development of society is greatly increasing. It is necessary to consider the advantages and disadvantages of their influence on the development of society while creating new breakthrough technologies. It is important to identify the arising problems in order to be sure in utilising full advantage of the benefits and minimize the negative consequences. Public management is dynamically developing within the system of interconnections between the municipalities [2-3], the local and state authorities and their interaction with democratic institutions. Municipalities are single urban administrative divisions having corporate status and powers of self-government or jurisdiction as granted by national and regional laws to which it is subordinate. The interconnection system based on the principles of independence and responsibility of all these units in the general system of public authority. Today's important task is to assess the risks of digital transformation in the social and economic systems management.

The system design of architectural models in public management look like a hot issue. The public management architectural model is a vision method that displays a complete picture of the organization and is used to synchronize strategic objectives and tactical needs

\footnotetext{
* Corresponding author: soft.rosko@mail.ru
} 
for value creation [4]. One of the most important components of the model is a value proposition (choice and satisfaction of customer needs).

\section{Materials and Methods}

Currently, a methodological chaos reigns in the definitions of the value concept and the interpretation of value relations regarding of public management field. Value is understood as a blessing for an individual, a group, an enterprise and / or a society in the sense of moving towards higher values or in the sense of protection against a shift in the opposite direction [5]. Value models should be applicable for the complex definition and control of the enterprise's development benchmarks, as well as managing emerging risks, including in digital transformation (DT) projects and during the operation of transformed organizations.

The set of value models for an organization should reflect a set of potentially heterogeneous values for all stakeholders, including those affected by the DT [6]. It includes an enterprise as an agent of the economy, its owners, employees, partners, customers, public organizations and government bodies.

The most complicated is the question of understanding the stakeholders and their values. It is necessary to describe the values so that the descriptors are clear, and the values can be compared.

To select the best solution, it is necessary to use integration of stakeholders models and their values and procedures for comparing values and reaching compromises in the value conflict points (fig.1).

\section{Stakeholders and their values}

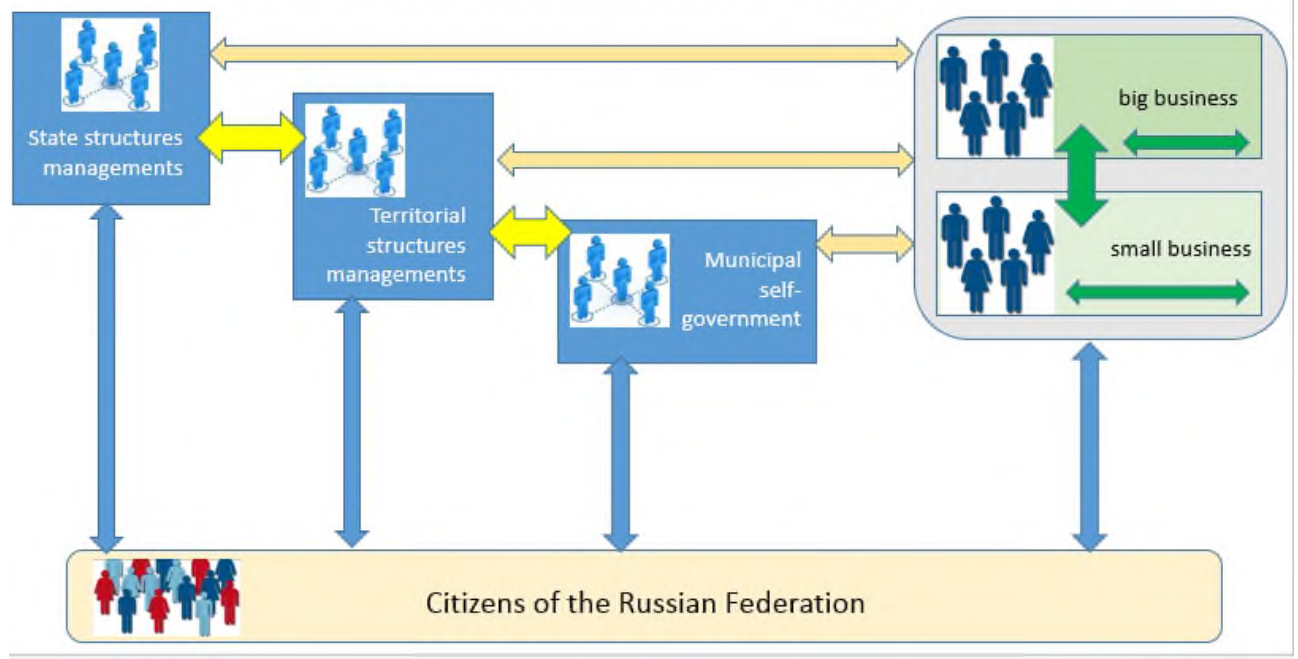

Fig. 1. Stakeholders and their values

The specific value should be described in terms of:

- the type of value (trust, responsibility etc.).

- the type of carrier (including group / individual in his role as the stakeholder).

- the category of the stakeholder's need for this value.

- the category of the environment where the stakeholder needs this value.

- the manner of behaviour (style) chosen by the stakeholder

- the shape of interest (realization) to the value significant for the stakeholder (for example, the value of "Interest" in the shape of the number of "likes") 
- the level of implementation (development) of the value related to the stakeholder (declared, displayed etc.) and the way it can be measured.

- the openness of the set of characteristics (for example, the assignment of value when applied to a business problem).

\section{Results}

After determining the values, a model of value proposition was developed based on the perspective of one of the specified actors of the field of activity - public management. This model is conveniently presented in the form of a business model template proposed by Osterwalder [7-8]. For the design, the Archi software package has been used (fig.2).

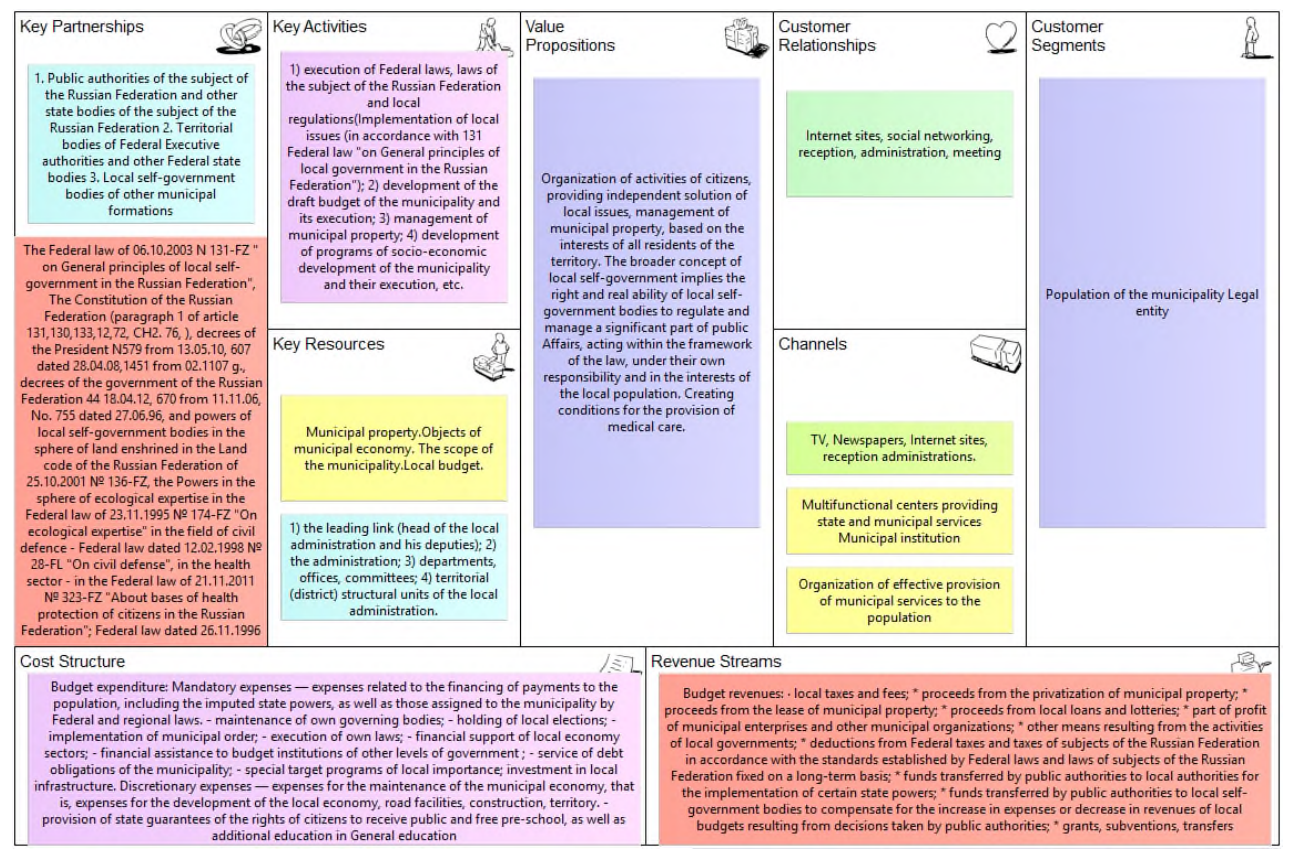

Fig. 2. A model of value proposition.

Consideration of this model is necessary through the problem map (fig.3) and the understanding of the value proposition. Constructing a context of problem map is the most difficult operation. This requires additional information about each actor. Collecting data about the actor is carried out automatically. This approach makes it possible to track the system intra-relations during a problem solving due to a value proposition and, accordingly, changes in the public management model. 


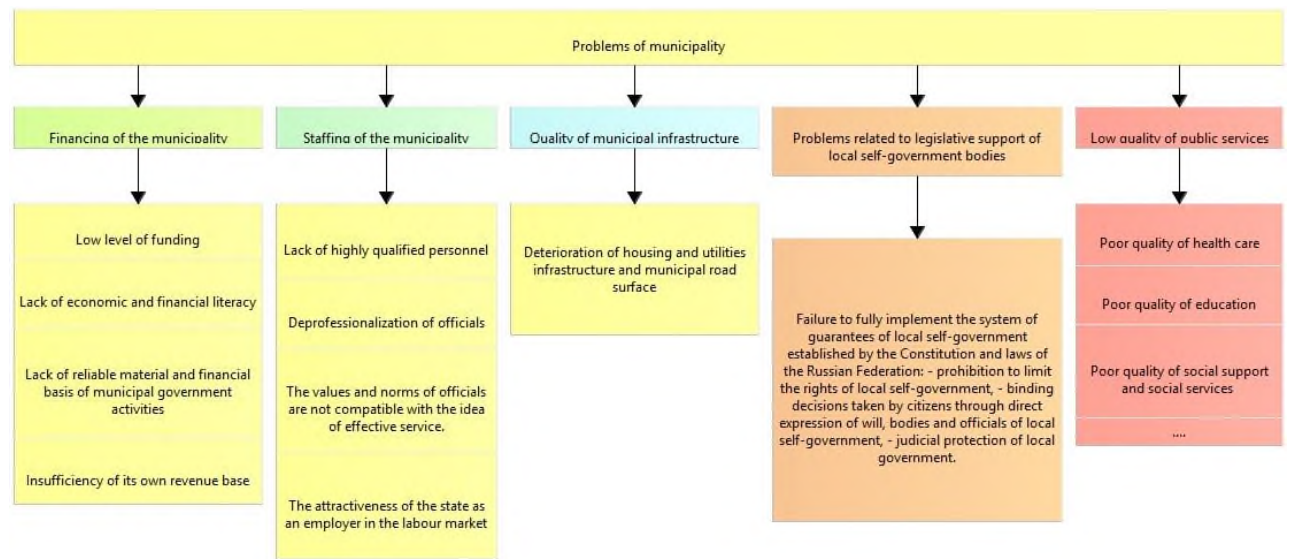

Fig. 3. The problem map.

To build a problem map, it is necessary to create an actor profile. The profile of the actor is built automatically on the basis of the information:

- about the actions of actors in the information space,

- logs of state information systems,

- expert assessments of the actions of the actor.

Based on the profile of the actor, all information is structured and grouped. For this purpose, it uses an algorithm based on decision trees. The resulting classification The resulting set of problems is classified manually. The use of automatic methods for the selection of knowledge has the worst characteristics.

For each actor, the most important criteria of interaction efficiency are highlighted. Criteria of efficiency of interaction are numerical values. For public management, the criteria are:

- expert evaluations of other actors,

- calculated indicators,

- performance indicators.

The calculated indicators are numerical indicators standardized by methods of indirect assessment of performance indicators. Performance indicators - value is directly calculated from the results for the reporting period.

All performance criteria are calculated automatically for each reporting period. The automatic rebuilding of the actor's profile allows the model of value proposition to be automatically rebuilt taking into account changes in the relations between the actors and the external environment. The text of changes in the of value proposition is created manually based on the interpretation of the changes received by the applicants. Experts for the main actors create the text of the changes. The context of the expert determines the quality of the transformation of numerical indicators of changes in management decisions and the actions of actors.

The relationship between the problem map and the map of value proposition should be interpreted as a global framework for the influence of the external environment on the formation of value by an actor in the described interaction model. Thus, the formation of management decisions for the implementation of the model of value propositions is formed for each problem independently of the others. Evaluation of the effectiveness of decisions taken at the next iteration step for restructuring the profile of each actor. The expert's actions are evaluated according to the dynamics of changes in the interaction effectiveness indicators and show the degree of knowledge extraction from the actors 'interaction system. 


\section{Discussions}

The challenge for Digital Transformation of the public administration is not primarily technological; it is largely a political challenge that must be guided from above [9]. Technology is a factor contributing to change, but "being digital" is only partly the product of technological activities. Behaviours, daily actions, culture, communication and leadership of the public administrations must adapt to the digital world. Citizens have the right to request greater simplicity, speed and transparency in the management of public services, and the State has a duty to provide services in a more modern and inclusive way. The country's development emanates mainly from cities; the major metropolitan areas are the nation's backbone and must fuel the digital transformation.

Although technology is fundamental and necessary for Digital Transformation, technology barriers many governments face prevent sometimes DT implementation [10]. European Commission (DIGIT Directorate-General for Informatics) includes in the DT transformation framework external technical support organization in order to ensure the technical interoperability. So in the large-scale digitalization projects, the technical services may form a consultancy hub for reducing cost.

\section{Conclusion}

Considering the model of values improvement, the process of change and the search for compromises must go from bottom to top. Ignoring and imposing values from top to bottom may lead to political and economic instability. Therefore, the activities of local governments can only be effective if the values of stakeholders are agreed upon population, business, local authorities, and government.

Economic problems hinder the progressive development of public management. As long as there is no stable financial basis for local government development and the economic dependence of public management from federal and regional state authorities still remains, the digital transformation model of local municipalities is unlikely to succeed. This means that the fate of a successful digital transformation conducted in the country today is directly dependent on the results of the search for effective mechanisms to strengthen the economic basis of local municipalities. In this regard, the authors consider it necessary to continue research towards the formation of the economic sovereignty of local municipalities.

The impossibility to exclude the work of experts in building a map of value proposition is associated with the need to work with knowledge. Formation of knowledge should take place continuously. The knowledge base of public management is currently one of the priority directions of development of the method of digital transformation of value propositions. Implicit knowledge of the actors has the greatest impact on the value map.

The method of digital transformation of the value map is a universal tool for matching and tracking the expectations of different-level actors in a complex system of interaction and allows bypassing the limitations of the mutual correlation of the actor and their social roles.

The use of big data processing technologies allows creating problem-oriented value maps taking into account the specifics of public management, mentality, cultural level and value of social group, increasing end-user satisfaction and reducing tensions between different social groups. 


\section{References}

1. M. Chantillon at al., Report: Managing the public sector Digital Transformation (International Hellenic University, Thessaloniki, Greece, 2017)

2. A. Seleznev, A. Mottaeva, L. Andreeva, S. Izmaylova, IOP Conf. Series: Earth and Environmental Science, 90, 012117 (2017), doi: 10.1088/1755-1315/90/1/012117

3. S. V. Petrova, E. V. Babeshkova, Problems and prospects of local government development in Russian Federation, Fundamental research. 6-1 (2016)

4. C. Talbot Public Value - The Next "Big Thing" in Public Management? International Journal of Public Administration, 32 (2009)

5. A. Mottaeva, A. Zheltenkov, MATEC Web of Conferences, 170, 01022 (2018) doi: $10.1051 /$ matecconf/201817001022

6. J. Ross, L. S. Flack, O. Sabo Stakeholder theory for the E-government context: Framing a value-oriented normative core. Government Information Quarterly, 35(3) (2018)

7. A. Osterwalder The Business Model Ontology: a proposition in a design science approach (PhD thesis). Université de Lausanne, Ecole des Hautes Etudes Commerciales. (2004)

8. A. Osterwalder, Y. Pigneur, Designing Business Models and Similar Strategic Objects: The Contribution of IS. Journal of the Association for Information Systems, 14 (2013)

9. https://teamdigitale.governo.it/assets/pdf/Report DigitalTransformationTeam 0930 2018.pdf (Last accessed 14.02.19)

10. http://go.opengov.com/ebook-digital-transformation-of-publicadministration.html (Last accessed 14.03.19) 